\title{
URBAN FLOOD RISK MANAGEMENT: IMPACT OF COMBINED STRATEGIES
}

\author{
FRANCO RAIMONDI ${ }^{1,2}$, MARIANA LOBO MARCHIONI ${ }^{1}$, CLAUDIA DRESTI $^{3}$, DARIO KIAN ${ }^{2}$, STEFANO $^{2}$ \\ MAMBRETTI $^{1,4} \&$ GIANFRANCO BECCIU ${ }^{1}$ \\ ${ }^{1}$ Politecnico di Milano, Italy \\ ${ }^{2}$ Ersaf, Italy \\ ${ }^{3}$ National Research Council, Water Research Institute, Italy \\ ${ }^{4}$ Wessex Institute of Technology, UK
}

\begin{abstract}
The sprawling of urban areas combined with the intensification of extreme storm events increases the frequency of floods. The Milan metropolitan area, Italy, is a glaring example of this condition, where floods occur on average two times a year and a new approach for urban water management is required. In recent years sustainable urban drainage systems (SuDs) have been spreading in many cities for local stormwater runoff reduction, in order to reduce the risk of overloading receiving water bodies and sewerage systems. These natural-based techniques also present advantages in terms of water quality improvement and in some cases also provide benefits at the ecological level. For an optimal river basin management, it is necessary to adopt holistic approaches including river restoration measures and $\mathrm{SuDs}$ for the hydraulic risk mitigation and the water and environmental quality enhancement. Previous research analysed the impact of re-naturalization measures on a stretch of the Seveso river on the flood risk for the urban area in Milan (Italy). Particularly, a potential reduction of $16 \%$ on the extent of the flooded area for 10 years return period events was assessed. In this case study benefits of additional measures of urban retrofitting based on parking areas de-sealing were investigated. To assess the effects, a rainfall-runoff process and a 2D flow simulation using SWMM and HEC-RAS software respectively were used. Results show, in particular, that transforming only the $2 \%$ of the Bresso municipality paved surfaces into permeable ones would achieve a reduction of both the peak and the volume of stormwater runoff, equal to $6.5 \%$ and $7.6 \%$ respectively, for 10 -year return period events. Moreover, a consequent reduction of 3 ha of flooded areas at the river watershed-scale was observed. Management of flood risk by a combination of river restoration and sustainable drainage systems is then confirmed to be a reliable strategy for the transition towards water sensitive cities also in very dense urban contexts as in the Milan area.
\end{abstract}

Keywords: environmental quality enhancement, flood risk mitigation, river contract, river restoration, spatial planning, sustainable drainage systems $(\mathrm{SuDs})$.

\section{INTRODUCTION}

Water is an essential resource for human life and easy access to water created along with history the ideal environment for the growth of entire civilizations. As urbanization grew, however, the presence of water became a source of impairment, related to flood and human health risks. Traditional urban water management concentrates then on the prompt conveyance of both wastewater and stormwater downstream away from urban areas through channels and pipes, so treating stormwater as waste product to be eliminated and urban watercourses as part of a wider sewage system. With this approach, waters of different nature and quality are regularly discharged into watercourses, directly or through combined sewers overflows (CSOs), with severe flood and pollution issues.

Over time though these strategies resulted unsustainable for the ongoing urban population and consequently urban areas growth. A possible new strategy is a holistic approach, based on the combination of sustainable drainage techniques (SuDs), morphological improvement of riverbed and riverbanks and the research for suburban areas suitable for being temporarily 
flooded during the most intense events. This approach can provide an adequate response to emergencies related to hydraulic risk and the loss of the natural functionality of rivers as well as provide benefits on local climate and represent a challenge on densely urban areas. River restoration strategies focus on regain ecological value and while preferring on-site management through the adoption of sustainable urban drainage systems (SuDs) promote stormwater source control and load removal. [1-3].

In this research, benefits of combined forces of river restoration and SuDs implementation, in particular, Permeable Pavement Systems (PPS), were investigated, through an application to Seveso River subcatchment in the Milan metropolitan area (Italy), which is characterized by high flood risk.

\section{BACKGROUND}

Seveso river has its spring in a regional park near the Como Lake and flows for about 50 $\mathrm{km}$ north of Milan where it becomes an underground channel which allows the transit of an estimated flow of not more than $30-40 \mathrm{~m}^{3} / \mathrm{s}$ up to the outlet in the Redefossi channel south of the city. Towards Milan, the course becomes almost completely artificial and rectified due to the heavy urban transformations that have affected the area since the 1960s. In particular, the portion of the basin between the North West Diversion Channel (CSNO) and the culvert channel of via Ornato in Milan (Fig. 1) has experienced a significant increase in soil waterproofing in last decades. The municipalities placed north of Milan have the highest population density rates in the whole region and make this area one of the most densely populated of Italy and Europe (Table 1). The metropolitan city expansion has increasingly reduced the river space and has led to the loss of its natural connotations, the deterioration of the water quality and the ecosystem and the increase in the flood risk also due to the intensification of higher frequency stormwater events.

Soil sealing, more than doubled from 1950 s to 1960 s, reduces drastically the percentage of rainwater infiltration and lowered the concentration time by increasing the surface runoff. On average, the area has been affected by floods twice a year from the 1960s to today. It

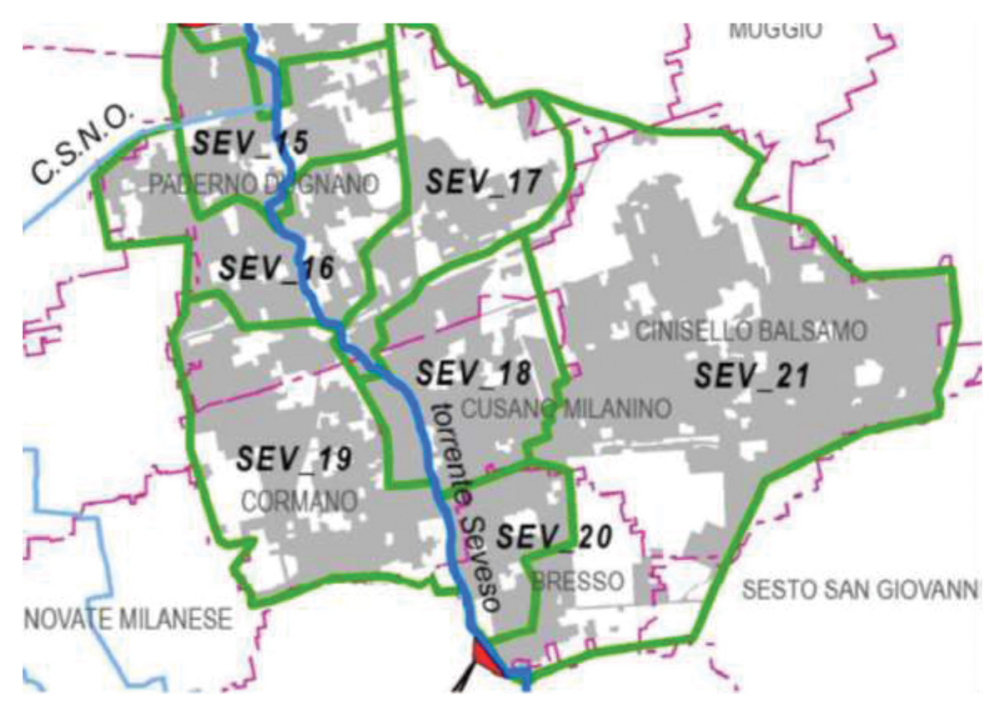

Figure 1: Seveso river sub-basin in the case study area, extract from AdbPo study [4]. 
Table 1: Characteristics of the municipalities in the case study area.

\begin{tabular}{lll}
\hline Municipality & Current urban area & Density $[\mathrm{ab} / \mathrm{km} 2]$ \\
\hline Paderno Dugnano & $70.6 \%$ & 3,318 \\
Cusano Milanino & $81.9 \%$ & 6,139 \\
Cormano & $69.9 \%$ & 4,482 \\
Bresso & $81.2 \%$ & 7,597 \\
Cinisello Balsamo & $75.0 \%$ & 5,827 \\
\hline
\end{tabular}

is therefore urgent to find solutions that allow for a reduction of flood risk and at the same time do not lead to the deterioration of the environment and water quality in a watershed and holistic perspective $[5,6]$.

\section{PERMEABLE PAVEMENT SYSTEMS (PPS)}

As a part of the SuDs, permeable pavement systems (PPS) allow water infiltration through their surfaces reducing runoff peak flow and volume and promoting load removal [3]. On a dense urban area PPS has the advantage to use paved areas that otherwise would contribute to runoff as detention and/or infiltration system. Rainwater infiltrates through its surfaces and is then stored on a permeable base slowly percolating through the subgrade or conveyed through drainage pipes reaching the next link of the stormwater management project [3]. Permeable interlocking concrete pavement, pervious asphalt and permeable concrete allow vehicular traffic and are most commonly used as PPS surfaces. Through the infiltration mechanism PPS reduces runoff, with runoff coefficients ranging from 0.00 (zero) to 0.45 on full-scale tests considering various surface materials and life use [3]. Laboratory rainfall simulation tests considering pervious asphalt and permeable concrete surfaces clogged with particulate matter (PM) showed no-runoff (zero runoff coefficient) on 69\% of the tests, where the slope resulted more relevant on increasing runoff than clogging conditions [7-9]. Moreover, it is well known that pervious pavements have the capability to delay runoff reducing peak discharge $[3,10]$. Finally, porous surfaces normally used on PPS also function as filter [9,11-15], promoting load removal that as a vector for contaminants as heavy metals [16], suspended solids [17] and nutrients.

\section{CASE STUDY}

The area chosen as the case study is the subcatchment of river Seveso north of Milan, between the CSNO and the culvert inlet in Via Ornato. A previous study was performed by the Authors for this area, on the effects of possible SuDs strategies [1]. In the present paper additional analyses are presented, to broaden the number of possible scenarios of interventions within the scope of the action plan of the Strategic Sub-Basin Project [18]. In [1], the effects related to the renaturalization of the riverbed and riverbanks in some sections, through the recalculation of the river functionality index (IFF) [19], and the hydraulic risk reduction through the creation of floodplain areas in the northern part of the municipality of Milan and in the neighbouring municipalities, were evaluated, following the hypothesis that no other intervention had been carried out upstream of the study area, including between the CSNO and the beginning of culvert in via Ornato in Milan. The hypothesized actions regarded in particular the morphological diversification of riverbed and riverbanks in five river sections through 
soil bioengineering operations (fascines, wickers, bush wattles, etc.), with the planting of shrub species suitable for the riparian environment or through the hydroseeding techniques; the creation of scrapers and the positioning of triangular boulders deflectors in the riverbed; the construction of four ecotonal buffers, of which two adjoining the water course, with a width of not less than 10 meters and a coverage area of $24,000 \mathrm{~m}^{2}$; the creation of three storage areas (areas A and C, 20,000 and 3,500 $\mathrm{m}^{2}$ respectively, in the municipality of Cormano, the first one on the hydrographic right, the second one on the hydrographic left and area B, $18,000 \mathrm{~m}^{2}$, in the municipality of Bresso) and the de-sealing of four car parking areas for a total of $13,000 \mathrm{~m}^{2}$. In [1], the recalculation of the IFF index has shown the enhancement of the river ecologic role while the reduction of the floodable areas obtained after the implementation of storage areas on the Seveso river floodplain was addressed with a 16\%, $13 \%$ and $26 \%$ reduction for 10, 100 and 500 years return period respectively compared to the current situation.

A further reduction in flood area could be obtained by implementing SuDs upstream, reducing the peak flow that reaches the river during a storm event. This research proposes a first retrofit scenario by implementing PPS on parking lots on the Bresso city subcatchment to obtain peak flow and then flood area reduction. The comparison between scenarios was held by rainfall-runoff and flow river simulations. With respect to the previous scenarios analysed in [1], the parking lots in the municipality of Cormano and Milan were excluded and three more parking lots were added in the municipality of Bresso for a total of about $13,000 \mathrm{~m}^{2}$ equal to $0.4 \%$ of the municipal area. The case study area remains the same but the conditions for calculating the inlet flows have changed. A 2017 study by the Po river District Basin Authority (AdbPo) [4] lists a series of rolling areas to be built along the entire course of the Seveso river whose realization, combined with the doubling of the flow rate of the CSNO, would result in the nullification of the Seveso flow downstream the CSNO itself. Consequently, the flow into the case study area is given by the runoff of the area itself which, given the high rate of urbanization, is still alone capable of causing flooding in Milan.

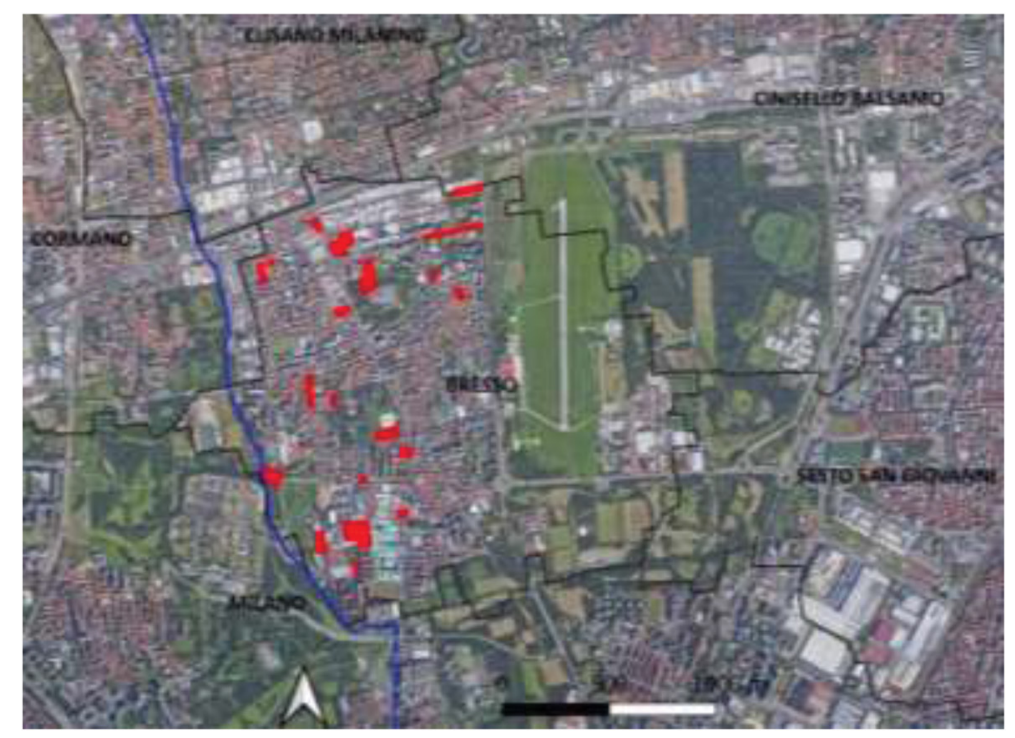

Figure 2: Parking areas in the municipality of Bresso. 
This study aims to determine the combined effectiveness in reducing hydraulic risk of river restoration strategies (the implementation of the storage areas) and sustainable drainage techniques, using PPS, first of all in the four parking areas proposed by the Bresso municipal administration (for a total of $13,000 \mathrm{~m}^{2}$, equal to $0.4 \%$ of the municipal area) and then considering the de-sealing of all car parks (for a total of about $64,000 \mathrm{~m}^{2}$, equal to $2 \%$ of the municipal area) (Fig. 2).

\section{MATERIALS AND METHODS}

The area covered by this study is shown in Fig. 1. The subdivision into sub-basins follows the one identified by the AdbPo study [4] based on the conformation of the underground water service network, so the sub-basins do not perfectly follow the municipal boundaries. The surface occupied by each sub-basin and the percentage of imperviousness are shown in Table 2. Each sub-basin corresponds to a single closure section placed on the watercourse, thus assuming that all the rainwater is delivered to the Seveso.

Rainfall-runoff processes were modelled using Storm Water Management Model (SWMM) software. SWMM is a dynamic rainfall-runoff software used for single event or long-term (continuous) simulation of runoff quantity and quality from primarily urban areas. The runoff block of SWMM operates on a collection of subcatchment areas that receive precipitation and generate runoff and pollutant loads. The routing block of SWMM transports this runoff through a system of pipes, channels, storage/treatment devices, pumps and regulators. SWMM tracks the quantity and quality of runoff generated within each subcatchment, and the flow rate, flow depth and quality of water in each pipe and channel during a simulation period [20,21]. The LID (low-impact-development) block of SWMM allows simulating the behaviour of some of the SuDs techniques, such as rain gardens, bio-retention cells, swales, green roofs and permeable pavements. In particular, to simulated PPS the typical values of $1,000 \mathrm{~mm} / \mathrm{h}$ for infiltration capacity and $750 \mathrm{~mm} / \mathrm{hr}$ for the permeable base were used [3]. The Seveso river has been schematized as an irregularly shaped open-air channel, each closing section has been made to correspond to a precise cross section of the Seveso among those used in hydraulic modelling with HEC-RAS [1] and the respective station-elevation profiles were then inserted as well as the roughness values for riverbed and riverbanks. The Horton method was chosen as the infiltration method with a range of infiltration rate of $0.5-5 \mathrm{~mm} / \mathrm{h}$, while the depressions storage existing on the surfaces has been set to 0 . A probabilistic method based on the use of the depth-duration-frequency curves, whose parameters are available on the ARPA site [22], municipality by municipality, was used to calculate the rainfall. For the simulation 10 and 100 years return period were used. The Chicago design storm with $24 \mathrm{~h}$ duration and 0.3 time to peak was considered. The evaluation of the effects of permeable pavements was first conducted by assuming the de-sealing of four car parks indicated by the Bresso municipal administration and then assuming the de-sealing of all the Bresso car parks identified employing satellite images. In the first case, the permeable area is equal to $0.9 \%$ of the total subcatchment area, in the second one to $4 \%$. The simulation of permeable parking lots was made possible in SWMM thanks to the presence of the LID control element. It was decided to consider the following layers and thicknesses in order from top to bottom: surface $(2.5 \mathrm{~mm})$, pavement $(100 \mathrm{~mm})$, soil $(200 \mathrm{~mm})$ and storage $(300 \mathrm{~mm})$. No underdrain has been selected and the clogging phenomenon has not been taken into account due to the rainfall short duration used for simulations. For the pavement permeability a value of $1,000 \mathrm{~mm} / \mathrm{h}$ has been chosen, the vegetation volume fraction was set equal to 0 , while permeable base was set equal to $750 \mathrm{~mm} / \mathrm{h}$. The analysis of the effect of de-sealing on the outflow was conducted only for the Bresso subcatchment, the only one interested in SuDs interventions. 
Table 2: Subcatchments total and impervious area.

\begin{tabular}{lll}
\hline Subcatchment & Total area $\left[\mathrm{km}^{2}\right]$ & \% impervious area \\
\hline SEV_15 (Paderno Dugnano) & 2.9 & 72 \\
SEV_16 (Paderno Dugnano) & 3.7 & 71 \\
SEV_17 (Paderno Dugnano) & 3.7 & 49 \\
SEV_18 (Cusano Milanino) & 3.7 & 73 \\
SEV_19 (Cormano) & 5.6 & 70 \\
SEV_20 (Bresso) & 1.6 & 81 \\
SEV_21 (Cinisello Balsamo) & 14.9 & 63 \\
\hline
\end{tabular}

For the hydraulic modelling, in order to evaluate the areas affected by flooding, a catchment model was developed in HEC-RAS [1]. The main features of the model are summarized below. The Digital Terrain Model presents a $20 \times 20$ resolution, for the evaluation of the terrain roughness reference was made to the classification of land use of the Lombardy Region (DUSAF) available on Geoportale of the Lombardy Region [23], while the riverbed and riverbanks roughness coefficients were drawn from literature $[24,25]$. The river cross sections have been imported by the Geoportale too and AdbPo site $[4,26]$, a square computational mesh of $20 \mathrm{~m}$ per side for the calculation of the floodable areas has been set, a $4 \times 2 \mathrm{~m}$ culvert with a maximum flow of $35 \mathrm{~m}^{3} / \mathrm{s}$ represents the starting point of the underground channel, three storage areas were created and the simulation has been carried out with the mixed 1D/2D method. Assuming the full implementation and functionality of the interventions envisaged in the AdbPo study [4] upstream the CSNO, the initial Seveso flow was set equal to 0 . The flow rate in the area under study is therefore given exclusively by the sum of the contributions of runoff water on the surfaces of the municipalities included between the CSNO and the culvert of via Ornato in Milan. SEV_15, SEV_16, SEV_17, SEV_18 and SEV_19 subcatchments have the closing section placed upstream the storage areas A and C, SEV_20 closing section placed upstream storage area B while SEV_21 closing section placed towards the culvert. The simulations involved events with return times of 10 and 100 years. For each return period the hydrograms leaving each subcatchment at the current state were calculated by SWMM. Only in the case of Bresso the hydrograms were calculated also in the hypothesis of the de-sealing of the four parking areas indicated by the municipal administration and the de-sealing of all car parks. These hydrograms were then used as input in HEC-RAS for the assessment of the flooded areas, obtaining four scenarios: current state (AdbPo interventions upstream the CSNO, with the only urban runoff to the formation of the flood [4]) (scenario 1), effects of the three storage areas only (scenario 2), combined effects of storage areas plus de-sealing of four car parks (scenario 3) and combined effects of storage areas plus de-sealing of all Bresso car parks (scenario 4).

\section{RESULTS AND DISCUSSION}

The results of the hydrological modelling in SWMM show, for a return time of 10 years, a reduction of peak flow downstream SEV_20 equal to 0.3 and $1 \mathrm{~m}^{3} / \mathrm{s}$ in the case of de-sealing of 4 car parks and of all the car parks in the Bresso municipality, respectively (Fig. 3). Concerning the volume, a reduction is observed from 184 to $181 \mathrm{~m}^{3}$ in the first case and to $170 \mathrm{~m}^{3}$ in the second one. The runoff coefficient decreases from $92.2 \%$ at the current state to $90.5 \%$ 


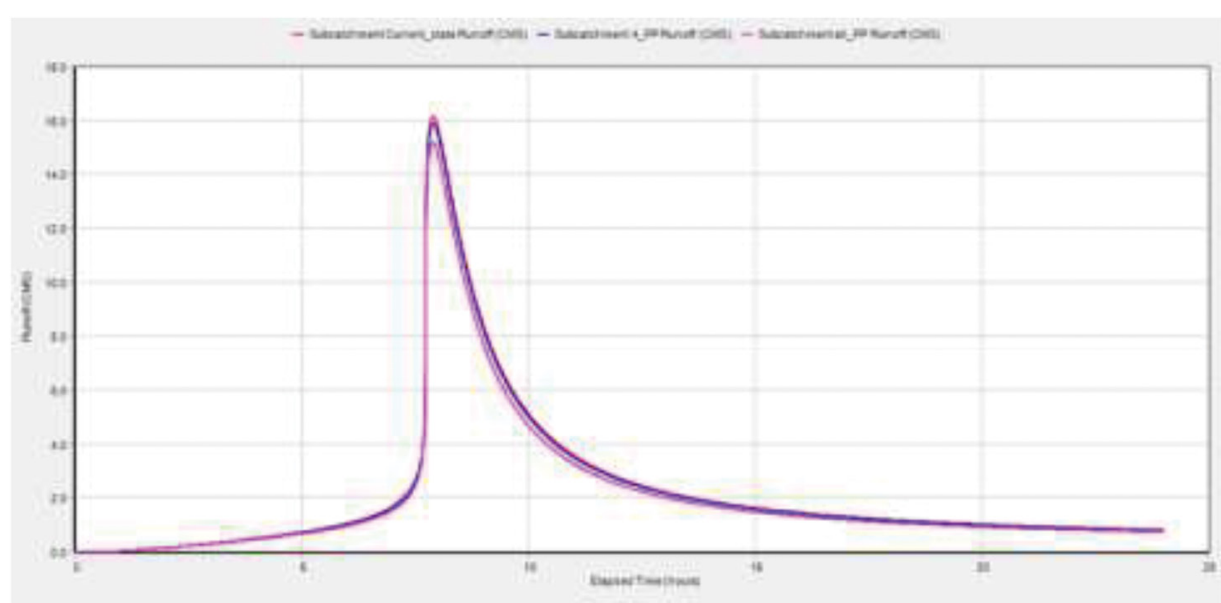

Figure 3: Runoff at the current state (red), with 4 PP (blue) and with the totality of PP (purple).

and finally to $85 \%$. No significant time shift of peak flow was observed. Results with the 100 years return period event were less significant in terms of peak flow and runoff volume reductions.

In the hydraulic simulations carried out in HEC-RAS the main differences concern scenario 1 (current state) and scenario 2 (only storage areas). While in the case of a return time of 100 years, the reduction of flooded areas is about $8 \%$, in the case of a return time of 10 years, a reduction of almost $1 \mathrm{~km}^{2}, 4 \mathrm{~h}$ later flood timing, corresponding to a percentage higher than $19 \%$, is obtained (Table 3). In terms of the flow velocity in the riverbed and in the flooded areas, there is substantial parity in the two scenarios, while the distribution of the water depth in the flooded areas is different. In fact, in scenario 2 the water depth is significantly lower (about $10 \mathrm{~cm}$ ) upstream of the culvert inlet with respect to scenario 1, while it is greater $(5-8 \mathrm{~cm})$ downstream of it. This could be explained in the fact that in scenario 1 there is a greater homogeneity in the distribution of water while in scenario 2 the storage areas are able to better retain the runoff waters of the subcatchment with upstream closure sections while they do not affect the runoff coming out of the Cinisello Balsamo subcatchment, which has the greatest flow rates due to the much greater surface area compared to the other subcatchments, and whose closing section is very close to the culvert. Finally, in scenario 2 there is a delay in the flood timing of about $30 \mathrm{~min}$. For scenarios 3 and 4, the results are reported only in the case of a meteoric event with a return time of 10 years because for the 100 years event the differences on this scale are not observable. In scenario 3 the reduction of flooded areas compared to scenario 2 is equal to $0.01 \mathrm{~km}^{2}$ while in scenario 4 to $0.3 \mathrm{~km}^{2}$, which translate into a decrease compared to scenario 1 of $19.5 \%$ and $19.9 \%$ respectively (Table 3 ).

There are no further differences regarding the water depth in the flooded areas and the flow velocity both in the riverbed and outside, just as the flood timing does not vary with respect to scenario 2 .

The presence of the storage areas is the determining factor that allows the main reduction of flooding extent, a lower water tie in the affected areas and delays of the flood timing, for return times not exceeding 10 years. The introduction of SuDs, in particular of PPS in this case, results in a fairly significant decrease in the stormwater runoff and the volume of water discharged, considering that de-sealing involves only $2 \%$ of the Bresso entire municipal area, 
Table 3: Flooded area reduction for each scenario.

\begin{tabular}{llll}
\hline Scenario & $\begin{array}{l}\text { Scenario } \\
\text { code }\end{array}$ & $\begin{array}{l}\text { Flooded } \\
\text { area }\left[\mathrm{km}^{2}\right]\end{array}$ & $\begin{array}{l}\text { \% variation from the } \\
\text { current scenario }\end{array}$ \\
\hline Current scenario (after CSNO) & 1 & 4.97 & \\
With storage areas & 2 & 4.01 & $-19.3 \%$ \\
Storage areas + 4 PPS (Bresso) & 3 & 4.00 & $-19.5 \%$ \\
$\begin{array}{l}\text { Storage areas + all parking lots with PPS } \\
\text { (Bresso) }\end{array}$ & 4 & 3.98 & $-19.9 \%$ \\
\hline
\end{tabular}

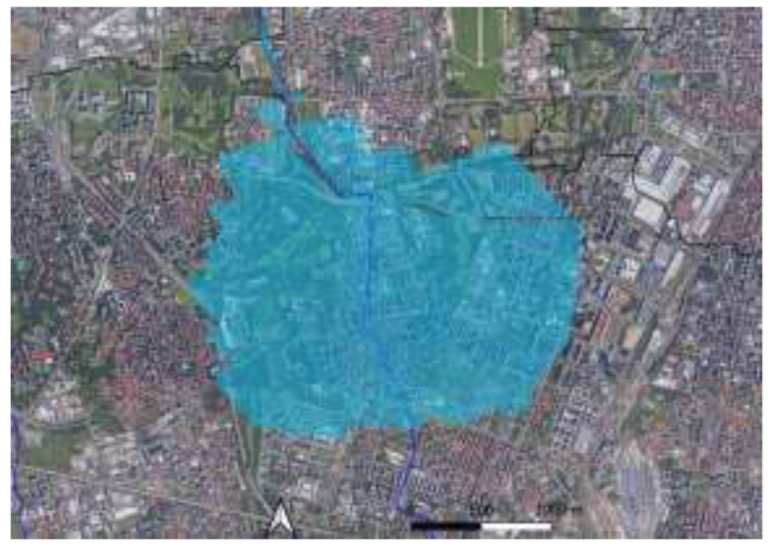

Figure 4: Flooded areas in scenario 1.

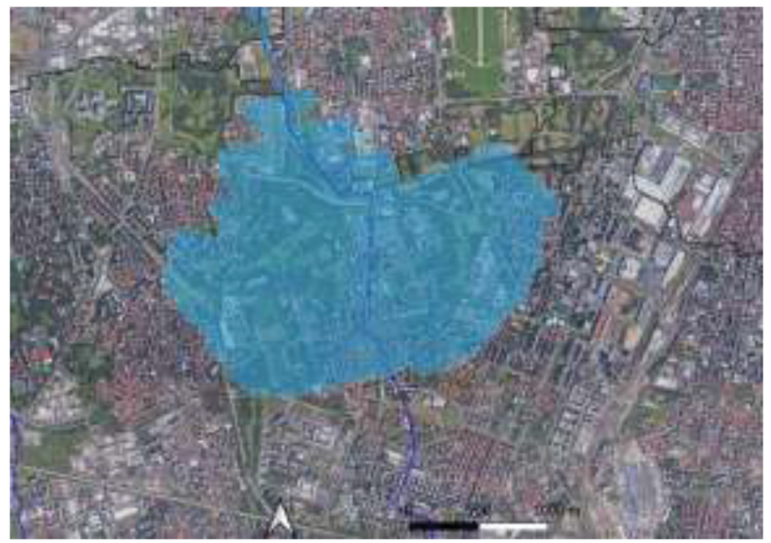

Figure 5: Flooded areas in scenario 2.

although not causing a shift in the hydrogram over time. At the case study area level, between the CSNO and the culvert, the PPS presence does not bring significant additional improvements to what has already been determined by the storage areas, however, a reduction of just under $0.1 \%$ of flooded areas was highlighted and it should be emphasized that it was obtained 


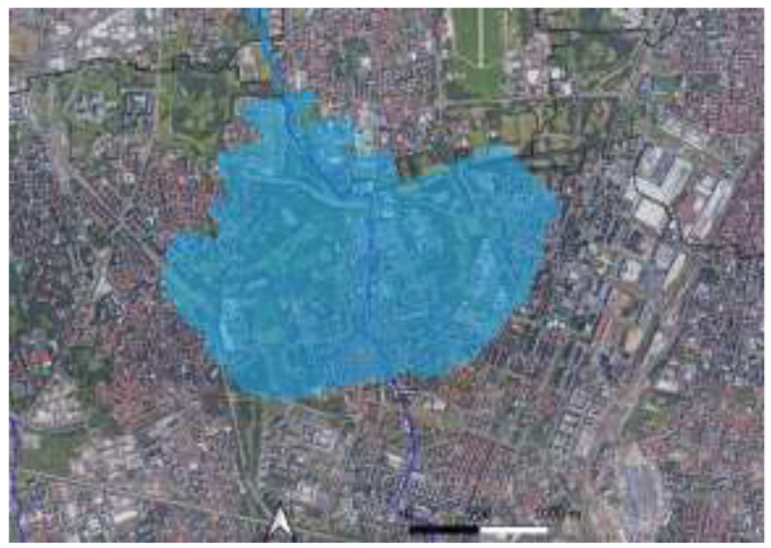

Figure 6: Flooded areas in scenario 4.

by intervening only on $2 \%$ of the surface of the municipality of Bresso which corresponds to just $0.18 \%$ of the entire case study area. In these terms, the effects of PPS introduction seem to be significant. The following figures (Figs. 4-6) show the areas affected by flooding $4 \mathrm{~h}$ after the start of the flood in the current case (scenario 1), with the introduction of storage areas only (scenario 2) and with the de-sealing of all the Bresso car parks (scenario 4).

Benefits achieved in the new analysed scenarios are additional to those already assessed in [1], relating to the improvement of the ecological functionality of the river and the quality of the water. These benefits can be briefly summarized as: increasing in self-purifying capacity thanks to the morphological diversification of the riverbed, improving coarse particulate organic matter retention [27], avoiding the formation of dead pools and of poor hygienic conditions, improving the formation of fundamental microhabitats $[28,29]$ for the restoration of macroinvertebrates [30], enhancing of photosynthetic productivity [31], providing a pretreatment of rainwater [32], stabilizing of riverbanks and providing sustenance for numerous species of birds and small mammals thanks to the ecotonal buffers. Moreover, SuDs techniques, in general, contribute to the removal of pollutants and, in particular, PPS are able to remove a wide range of pollutants [10-12,15-17].

\section{CONCLUSIONS}

The effects of river restoration techniques on flood risk in the metropolitan area of the Seveso river basin were analysed. Particularly, the reduction of flood risk achievable by the implementation of SuDs techniques in the urban part of the catchment was assessed. With respect to previous studies [1], new scenarios with the retrofit of existing parking areas in the Bresso municipality with PPS were considered. Rainfall-runoff processes were simulated using SWMM for a 10-year return period event. The flooding processes were simulated by HECRAS. The PPS implementation would result in a peak flow reduction of $1 \mathrm{~m}^{3}$ and a flooded area reduction of $0.1 \%$. Although the effect may seem not so important it is necessary to consider that the soil de-sealing involved only $0.18 \%$ of the total case study area. Moreover, the reduction of the total catchment runoff coefficient is of about $7 \%$ with the outflow volume decreased of $14 \mathrm{~m}^{3}$.

Moreover, PPS and SuDs, in general, provide benefits beyond the runoff peak flow and volume reduction, such as load removal, groundwater recharge, providing habitat for urban 
vegetation and facilitating evapotranspiration. Results showed that to achieve sustainable stormwater and flood risk management a pool of integrated solutions should be addressed. Although each small-scale intervention can have limited results, the effects may be amplified by the synergy at the catchment scale. In a strongly anthropized environment implementing river restoration projects and SuDs techniques, can result not only in more efficient addressing of flood risk but also in gaining ecological value, in improving river water quality and in developing a better adaptation to climate change. Further gain could be achieved by applying flow-limit regulations [33] already available in the study area. This study confirms the conclusion presented in [1] about the goodness of this purpose and the effectiveness of the co-planning process with the local actors identified by the Lombardy Region in the Sub-basin Strategic Project [18]. Further investigation could be done in the future to find and test more SuDs solutions in the other subcatchments assessing the results for continuous simulations and for event with lower return period in order to enhance and disseminated the holistic approach necessary to solve critical issues regarding hydraulic risk and water and environmental quality in urban areas.

\section{REFERENCES}

[1] Raimondi, F., Dresti, C., Marchioni, M.L., Kian, D., Mambretti, S. \& Becciu, G., Integrated strategies for river restoration and land re-naturalization in urban areas: a case study in Milan. WIT Transactions on the Built Environment, 194, pp. 23-34, 2020. https://doi.org/10.2495/FRIAR200031.

[2] Marchioni, M.L. \& Becciu, G., Permeable pavement used on sustainable drainage systems (SUDs): a synthetic review of recent literature, WIT Transactions on the Built Environment, 139, p. 12, 2014. http://dx.doi.org/10.2495/uw140161.

[3] Marchioni M., Becciu G., Experimental results on permeable pavements in urban areas: a synthetic review, Int. Journal of Sustainable Development and Planning, 10(6), pp. 806-817, 2015. https://doi.org/10.2495/SDP-V10-N6-806-817.

[4] Autorità di bacino distrettuale del fiume Po, Allegato 3 alla relazione tecnica del progetto di variante al pai del torrente Seveso, 2017, www.adbpo.gov.it (in Italian).

[5] Becciu, G., Ghia, M. \& Mambretti, S., A century of works on River Seveso: from unregulated development to basin reclamation. International Journal of Environmental Impacts, 1(4), pp. 461-472, 2018. https://doi.org/10.2495/EI-V1-N4-461-472.

[6] Lawson, E., Thorne, C., Ahilan, S., Allen, D., Arthur, S., Everett, G., Fenner, R., Glenis, V., Guan, D., Hoang, L., Kilsby, C., Lamond, J., Mant, J., Maskrey, S., Mount, N., Sleigh, A., Smith, L. \& Wright, N., Delivering and evaluating the multiple flood risk benefits in blue-green cities: an interdisciplinary approach. WIT Transactions on Ecology and the Environment, 184, pp. 113-124, 2014

[7] Brugin, M., et al., Clogging potential evaluation of porous mixture surfaces used in permeable pavement systems. European Journal of Environmental and Civil Engineering, pp. 620-630, 2020.

[8] Andrés-Valeri, Valerio C., et al., Laboratory assessment of the infiltration capacity reduction in clogged porous mixture surfaces. Sustainability, 2016.

[9] Marchioni, M., et al., Laboratory study on the rainfall influence over the sediment transport dynamics on pervious pavements' discharge. Urban Water System Floods 165, pp. 165-176, 2016.

[10] Pratt, C.J., Mantle, J. \& Schofield, P., UK research into the performance of permeable pavement, reservoir structures in controlling stormwater discharge quantity and quality. 
Water Science and Technology, 32(1), pp. 63-69, 1995. https://doi.org/10.1016/02731223(95)00539-y

[11] Sansalone, JJ. \& Buchberger, SG., Partitioning and first flush of metals in urban roadway storm water. Journal of Environmental Engineering, 123(2), pp. 134-143, 1997.

[12] Sansalone, John J., et al., Physical characteristics of urban roadway solids transported during rain events. Journal of Environmental Engineering, 124(5), pp. 427-440, 1998.

[13] Sansalone, J., Kuang, X., \& Ranieri, V., Permeable pavement as a hydraulic and filtration interface for urban drainage. Journal of Irrigation and Drainage Engineering, 134(5), pp. 666-674, 2008.

[14] Fedele, V., et al., Computational fluid dynamics as a tool to estimate hydraulic conductivity of permeable asphalts. Transportation Research Record 2674.8, pp. 370-383, 2020.

[15] Sansalone, JJ., Buchberger, SG., \& Al-Abed, S.R., Fractionation of heavy metals in pavement runoff. Science of the Total Environment, 189, pp. 371-378, 1996.

[16] Legret, M. \& Colandini, V., Effects of a porous pavement with reservoir structure on runoff water: water quality and fate of heavy metals. Water Science and Technology, 39(2), pp. 111-117, 1999. http://dx.doi.org/10.1016/s0273-1223(99)00014-1

[17] Pratt, C.J., Permeable pavements for stormwater quality enhancement. Urban Stormwater Quality Enhancement - Source Control, Retrofitting, and Combined Sewer Technology, ASCE, 1990.

[18] Regione Lombardia, ERSAF, Progetto Strategico di Sottobacino del torrente Seveso, 2017, www.contrattidifiume.it (in Italian).

[19] ISPRA, IFF 2007-indice di funzionalità fluviale, 2007, www.isprambiente.gov.it (in Italian).

[20] Rossman, Lewis A., Modeling low impact development alternatives with SWMM, Journal of Water Management Modeling, 2010.

[21] McCutcheon, M., \& Wride, D., Shades of green: using SWMM LID controls to simulate green infrastructure. Journal of Water Management Modeling, 2013.

[22] Agenzia Regionale per la Protezione Ambientale, www.arpalombardia.it

[23] Geoportale Regione Lombardia, www.geoportale.regione.lombardia.it/download-dati

[24] Chow, V.T., Open Channel Hydraulics, McGraw-Hill: New York, pp. 101-125, 1994.

[25] Cowan W.L., Estimating hydraulic roughness coefficients. Agricultural Engineering, 37, n 7, 1956.

[26] Autorità di bacino distrettuale del fiume Po, Piano di Gestione del Rischio Alluvioni, 2015, www.adbpo.gov.it (in Italian).

[27] Lepori, F., Palm, D., \& Malmqvist, B., Effects of stream restoration on ecosystem functioning: detritus retentiveness and decomposition. Journal of Applied Ecology, 42, pp. 228-238, 2005. https://doi.org/10.1111/j.1365-2664.2004.00965.x.

[28] Groll, M., Relations between the microscale riverbed morphology and the macrozoobenthos - implications for the ecological quality assessment and the definition of reference conditions, International Journal of Environmental Impacts, 1(3), pp. 375-389, 2018. https://doi.org/10.2495/EI-V1-N3-375-389.

[29] Purcell, Alison H., Friedrich, C. \& Resh, Vincent H., An Assessment on a Small Urban Stream Restoration Project in Northern California, Restoration Ecology, 2002. https:// doi.org/10.1046/j.1526-100X.2002.01049.x.

[30] Wallace, J.B. \& Webster, J.R., The role of macroinvertebrates in stream ecosystem function. Annual Review of Entomology, 41, pp. 115-139, 1996. https://doi.org/10.1146/annurev.en.41.010196.000555. 
[31] Jarvie, H.P., Love, A.J., Williams, R.J. \& Neal, C., Measuring in-stream productivity: the potential of continuous chlorophyll and dissolved oxygen monitoring for assessing the ecological status of surface waters, Water Science and Technology, 48(10), pp. 191-198, 2003.

[32] Schmid B.H., Innocenti I., Sanfilippo U., Characterizing solute transport with transient storage across a range of experiments in Austrian and Italian streams, Advances in Water Resources, 33, pp. 1340-1346, 2010.

[33] Regione Lombardia, Regolamento recante criteri e metodi per il rispetto del principio dell'invarianza idraulica ed idrologica, 2017, www.regione.lombardia.it (in Italian). 